\title{
The forthcoming era of precision medicine
}

\author{
Stjepan Gamulin \\ Croatian Academy of Sciences and Arts \\ Zagreb, Croatia \\ Correspondence: \\ sgamulin@hazu.hr \\ Tel.: + 38516588094 \\ Fax.: + 38514819979
}

Received: 20 October 2016

Accepted: 13 November 2016

Key words: Personalized medicine • Precision medicine.

\begin{abstract}
The aim of this essay is to present the definition and principles of personalized or precision medicine, the perspective and barriers to its development and clinical application. The implementation of precision medicine in health care requires the coordinated efforts of all health care stakeholders (the biomedical community, government, regulatory bodies, patients' groups). Particularly, translational research with the integration of genomic and comprehensive data from all levels of the organism ("big data"), development of bioinformatics platforms enabling network analysis of disease etiopathogenesis, development of a legislative framework for handling personal data, and new paradigms of medical education are necessary for successful application of the concept of precision medicine in health care. Conclusion. In the present and future era of precision medicine, the collaboration of all participants in health care is necessary for its realization, resulting in improvement of diagnosis, prevention and therapy, based on a holistic, individually tailored approach.
\end{abstract}

\section{Introduction}

Understanding of human genomes has given rise to the concept of personalized medicine, in which individual data on genomics, proteomics and the environment are integrated and applied to personal health care: diagnosis, prevention and treatment (1). Personalized medicine is widely accepted, but only superficially realized, mostly as the application of molecular (genomic, proteomic) biomarkers in prevention, diagnosis and therapy. On the basis of prognostic and predictive factors, patients are divided into subgroups that have a greater likelihood of an accurate diagnosis or favorable outcome. The choice of treatment for breast cancer (chemotherapy or hormonal therapy), according to the content of steroid receptors in the breast was one of the earliest such methods. It was introduced, in our country too, long before the concept of personalized medicine was launched (2). Until now, there have only been a few cases when the proper diagnosis was established on the basis of personal genomes, and appropriate and successful treatment applied (3). There is no doubt that medicine has always been personalized, at least to some extent. Physicians approach their patients as integral personalities, with inherent biological, psychological, mental and social characteristics and values. Therefore, the term "personalized medicine" is increasingly being replaced by the term "precision medicine".

The aim of this essay is to present a definition and the principles of personalized or precision medicine, its perspectives and the ways it may be implemented in health care. 


\section{Precision medicine: definition and implementation in health care}

In the Precision Medicine Initiative Cohort Project, precision medicine is defined as follows:

"We define precision medicine as an approach to disease treatment and prevention that seeks to maximize effectiveness by taking into account individual variability in genes, environment, and lifestyle. Precision medicine endeavors to redefine our understanding of disease onset and progression, treatment response, and health outcomes through the more precise measurement of potential contributors - for example, molecular measurements as captured through DNA sequencing technologies or environmental exposures, or other information captured through increasingly ubiquitous mobile devices. A precise delineation of the molecular, environmental, behavioral, and other factors that contribute to health and disease will lead to more accurate diagnoses, more rational disease prevention strategies, better treatment selection, and the development of novel therapies "(4).
The adage "easy to write, difficult to implement" best describes the current circumstances regarding the realization of the concept of personalized or precision medicine; there are countless obstacles on its path (5). Overcoming them requires, amongst other things, the development of personal genomics, translational research that will transfer basic knowledge to clinical applications, a new taxonomy of disease, based on molecular disorders, auditing of clinical trials with the subsets of patients selected according to new prognostic and predictive factors, the creation of genomics, proteomics and tissue biobanks, collecting comprehensive uniform clinical data ("big data") and the development of bioinformatics systems that will integrate clinical data with the comprehensive knowledge of the pathogenic factors (6, 7 ) and build a functional network of disease etiopathogenesis at the population and individual levels. Also, the legal basis of the use of individual data should be added, which will be required for the realization of the concept of precision medicine (8). All these

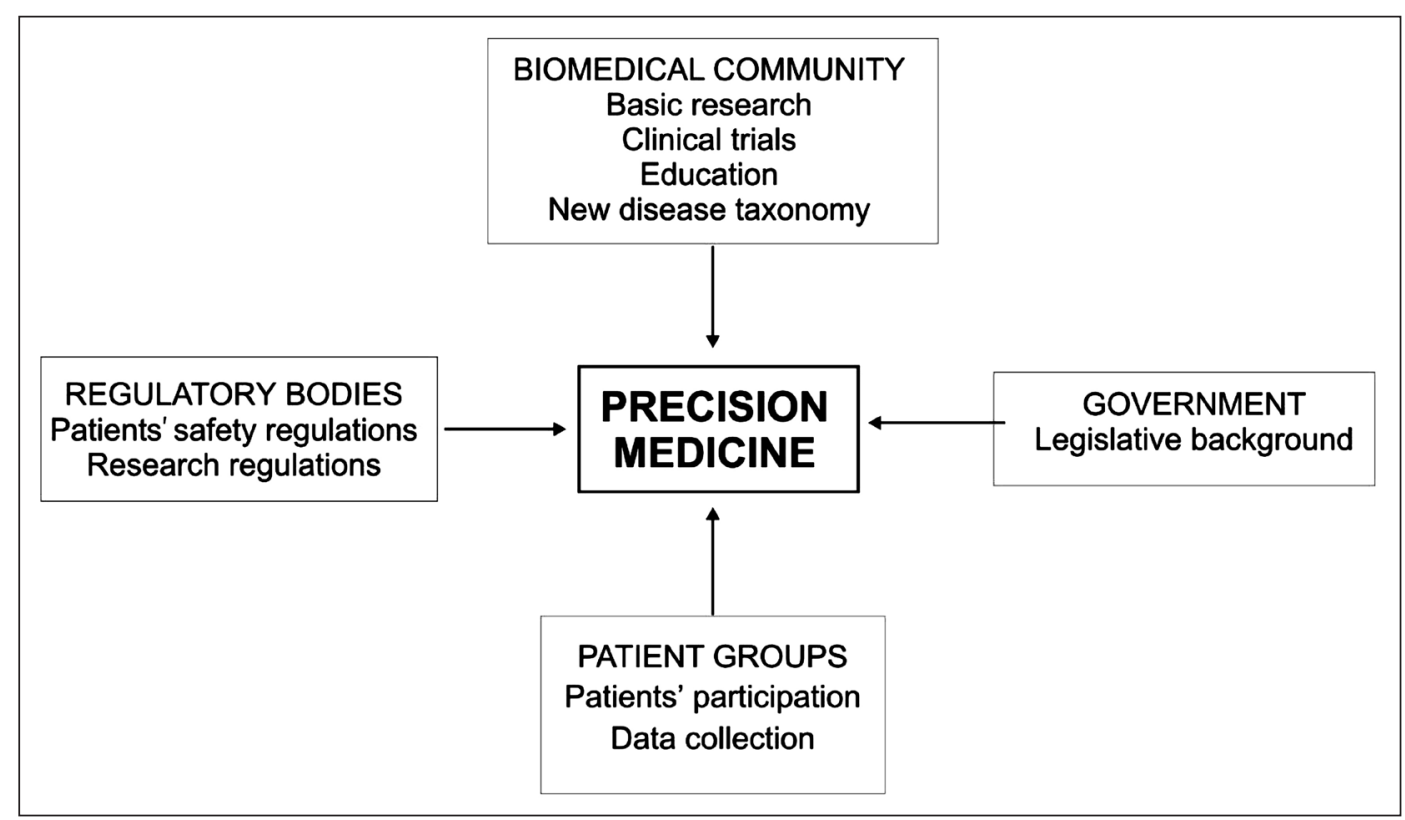

Figure 1 The major tasks of health care stakeholders involved in the progress of precision medicine. 
present a major challenge to all health care stakeholders (Figure 1) (9).

In the world, particularly in the United Kingdom and the United States, encouraged by parliaments and governments, great exploratory, financial and organizational efforts are being made to realize the concept of personalized or precision medicine. In the United Kingdom, in 2009 the House of Lords conducted an investigation on the state of the application of genomics in medicine, and in 2012 there followed an action plan on the application of genomics in health care (10).

In the United States, in 2008 the President's council of advisors on science and technology submitted to President Bush a report on the priorities of personalized medicine (11). The personalized medicine acts which followed in 2008 and 2010 had the aim of personalizing medicine in health care, so that it would be available to every American. The acts determined an action program, program management, the role of government agencies and financing (about 50,000,000 \$ per year) (12). President Obama, in his address to the nation in January 2015, announced the precision medicine initiative with a fund of 215 million \$ in 2016, with the aim to "pioneer a new model of patient-powered research that promises to accelerate biomedical discoveries and provide clinicians with new tools, knowledge, and therapies to select which treatments will work best for which patients"(13). In September 2015 the cohort structure program was published, comprising a million or more patients, and to be followed for 10 or more years (Precision Medicine Initiative Cohort Project, PMI-CP). "PMI-CP will be powered to identify biomarkers that are predictive of future development of a large number of diseases, affording new opportunity for disease prevention and therapy, as well as to provide new understanding of the factors that predict variation in response to current therapies for prevalent disease. Moreover, a design that allows participants to be recontacted for further study based on individual findings provides an invaluable opportunity to understand biological mechanisms that link biomarkers to traits in individuals "(4).

Genomics stands as the foundation of personalized or precision medicine (14). DNA sequencing technology is developing rapidly; the price of sequencing is rapidly decreasing and the speed increasing (15). This enables the implementation of the personal genome project in which a global network is planned of institutions providing genome sequencing of 100,000 people, with the collection of the detailed demographic and health data necessary for research of genotype - phenotype relationships (16).

The huge amount of very diverse data from all hierarchical levels of the organization of the organism (molecular, subcellular, cellular, humoral, organic, organismic), functional totalities (genome, trascriptome, proteome, metabolome, microbiome, phenome and other "omics"), and the mental, spiritual, social, environmental domains should be united at population and individual levels in systems that will explain disease etiopathogenesis in general and individually, allowing an individual approach to each person in all aspects of health care. For such an analysis it is necessary to develop bioinformatics systems by applying systems of medicine that build a functional networks. They will explain in detail the interaction between these factors in integrative ways, combining the functional networks of different organizational levels in a complete, functional system (17). The enormous number of factors, links and nodes of these networks make it difficult to understand them without bioinformatics support. However, it is sufficient to identify essential nodes (about 20\%) to define the function network (18). The interactions of important nodes can be displayed in a simplified network which summarizes 


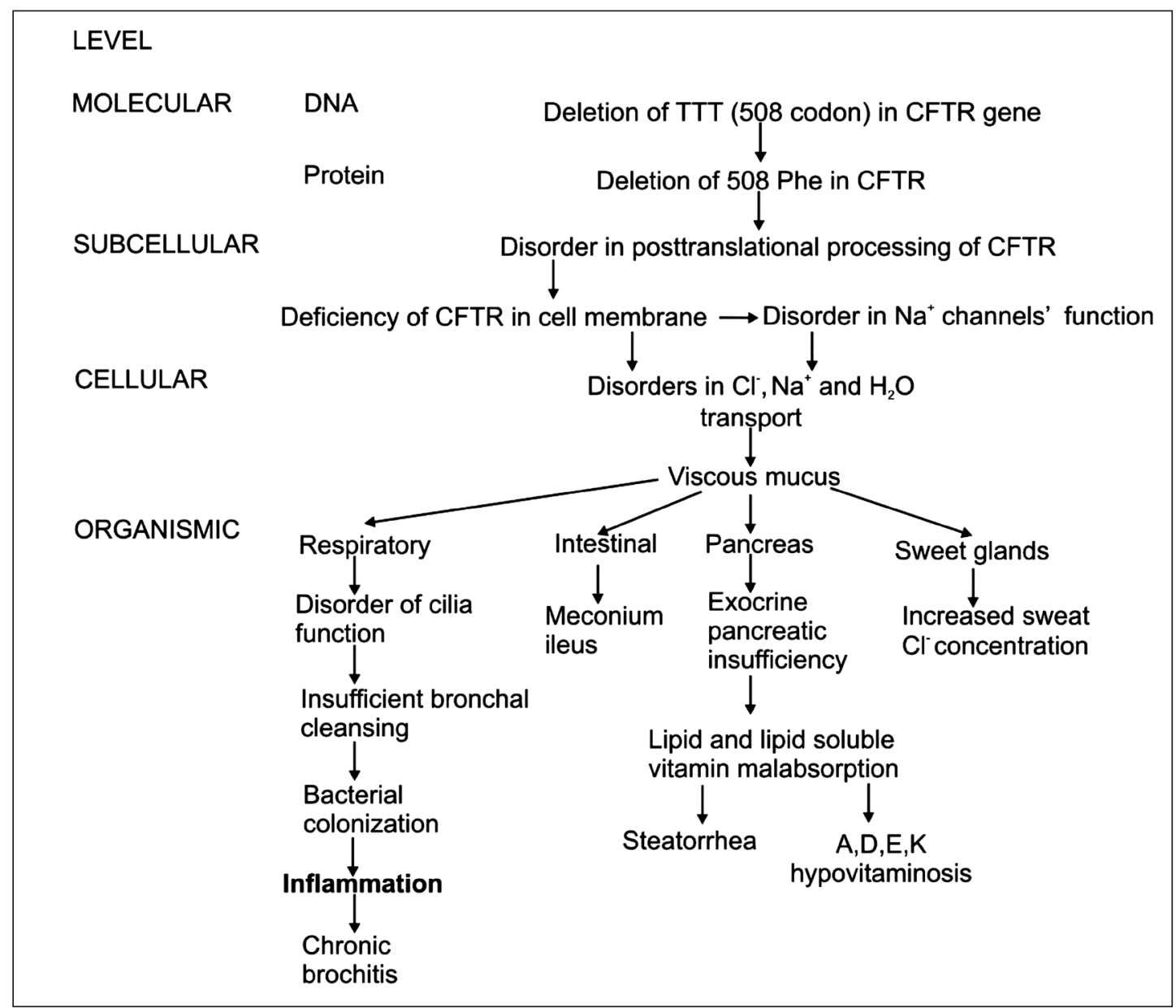

Figure 2 Vertical analysis of cystic fibrosis pathogenesis, for details see (20).

the detailed basic network allowing an overview of disease etiopathogenesis. Analyzing the disease etiopathogenes on this way, it is important to recognize the pathogenetic processes on the subsequent levels of organization of the organism, and integrate them vertically (along hierarchical levels) and horizontally (within the levels) (Figure 2) $(19,20)$.

The vertical analysis of disease pathogenesis integrates the basic genomic level with all subsequent levels and "omics", enabling interpretation of the influence of genomics on pathogenesis, and its application in clinical medicine.

\section{Precision medicine: its impact on medical education}

In order to be able to understand personalized or precision medicine, and accept and apply it, new paradigms in medical education (undergraduate, postgraduate, continuous) are required. Problem-solving education, including network analysis is appropriate for the complexity of the subject. Such an educational method has been developed at the School of Medical of the University of Zagreb, for problem-solving teaching of pathophysiology (21-23). Exercises are based on data presentation and 
their algorithmic analysis in terms of etiopathogenetic mechanisms, leading to manifestation of signs and symptoms. In this way students gain competence in vertical analysis, enabling them to understand the disease mechanisms, from the basic molecular level to the whole body level, expressing disease manifestations. Appropriate adjusted algorithmic analysis also enables analysis of the individual variability of personal characteristics, causal factors, therapeutic procedures and consequent outcomes, providing the path to understanding personalized or precision medicine.

\section{Conclusion}

Realization of the concept of personalized or precision medicine requires the coordinated effort of all health care stakeholders. Among other things, it requires translational research, with integration of personal as well as population genomics and comprehensive data from all organization levels of the organism ("big data"), the development of an appropriate bioinformatics platform, enabling the building of functional networks of the detailed etiopathogenesis of the disease, and the development of a legislative framework governing the establishment of personal data databases, which would be used in global networks involved in the implementation of precision medicine. Also new paradigms in medical education are required, enabling students to understand, accept and apply an integrative approach to health care, in accordance with precision medicine.

\section{References}

1. NIH, National Cancer Institute [homepage on the Internet]. Definition of personalized medicine NCI Dictionary of Cancer Terms [cited 2016 Apr 20]. Available from: http://www.cancer.gov/publications/dictionaries/cancer-terms?cdrid $=5$.
2. Gamulin S. Molecular mechanism of steroid hormones action: clinical implications [in Croatian]. Lijec Vjesn. 1975;97(12):679-82.

3. Worthey EA, Mayer AN, Syverson GD, Helbling D, Bonacci BB, Decker B, et al. Making a definitive diagnosis: successful clinical application of whole exome sequencing in a child with intractable inflammatory bowel disease. Genet Med. 2011;13(3):255-62.

4. NIH, National Institute of Health [homepage on the Internet]. Precision Medicine Initiative (PMI) Working Group Report to the Advisory Committee to the Director, NIH. The Precision Medicine Initiative Cohort Program - Building a Research Foundation for 21st Century Medicine [cited 2016 Apr 20]. Available from: http://acd.od.nih.gov/reports/DRAFT-PMI-WG-Report-9-11-2015-508. pdf.

5. Hamburg MA, Collins FS. The path to personalized medicine. N Engl J Med. 2010;363(4):301-4.

6. Noor AM, Holmberg L, Gillett C, Grigoriadis A. Big Data: the challenge for small research groups in the era of cancer genomics. Br J Cancer. 2015;113(10):1405-12.

7. Rumsfeld JS, Joynt KE, Maddox TM. Big data analytics to improve cardiovascular care: promise and challenges. Nat Rev Cardiol. 2016;13(6):350-9.

8. PMC [homepage on the Internet]. Personalized Medicine Coalition. The Case for Personalized Medicine, 4th edition, 2014 [cited 2016 Apr 20]. Available from: http://www.personalizedmedicinecoalition.org/Userfiles/PMC-Corporate/file/ pmc_the_case_for_personalized_medicine.pdf.

9. Mirnezami R, Nicholson J, Darzi A. Preparing for precision medicine. $\mathrm{N}$ Engl $\mathrm{J}$ Med. 2012;366(6):489-91.

10. GOV.UK [homepage on the Internet]. Human Genomics Strategy Group. Building on our inheritance. Genomic technology in healthcare, 2012 [cited 2016 Apr 20]. Available from: https://www. gov.uk/government/uploads/system/uploads/attachment_data/file/213705/dh_132382.pdf.

11. The White House [homepage on the Internet]. President's council of advisors on science and technology. Priorities for Personalized Medicine, 2008 [cited 2016 Apr 20]. Available from: https:// www.whitehouse.gov/files/documents/ostp/ PCAST/pcast_report_v2.pdf.

12. GovTrack [homepage on the Internet]. Genomics and Personalized Medicine Act of 2010 [cited 2016 Apr 20]. Available from: https://www.govtrack.us/congress/bills/111/hr5440/text/ih.

13. The White House [homepage on the Internet]. Office of the Press Secretary. FACT SHEET: President 
Obama's Precision Medicine Initiative [cited 2016 Apr 20]. Available from: https://www.whitehouse. gov/the-press-office/2015/01/30/fact-sheet-president-obama-s-precision-medicine-initiative.

14. Aronson SJ, Rehm HL. Building the foundation for genomics in precision medicine. Nature. 2015;526(7573):336-42.

15. Lunshof, JE, Bobe J, Aach J, Angrist M, Thakuria JV, Vorhaus DB, et al. Personal genomes in progress: from the Human Genome Project to the Personal Genome Project. Dialogues in Clinical Neuroscience 2010;12(1):47-60.

16. Personal Genome Project [homepage on the Internet] [cited 2016 Apr 20]. Available from: http:// www.personalgenomes.org.

17. Hood L, Flores M. A personal view on systems medicine and the emergence of proactive $\mathrm{P} 4$ medicine: predictive, preventive, personalized and participatory. N Biotechnol. 2012;29(6):613-24.
18. Goh KI, Cusick ME, Valle D, Childs B, Vidal M, Barabási AL. The human disease network. Proc Natl Acad Sci U S A. 2007;104(21):8685-90.

19. Blois MS. Medicine and the nature of vertical reasoning. N Engl J Med. 1988;318(13):847-51.

20. Gamulin S. Kovač Z. Principles of pathogenetic mechanisms [in Croatian]. In: Gamulin S, Marušić M, Kovač Z, editors. Pathophysiology. 7th ed. Zagreb: Medicinska naklada; 2011. p. 30-40.

21. Kovač Z, Gamulin S and associates. Pathophysiology - exercises for problem solving seminars [in Croatian]. Zagreb: Medicinska naklada; 2003.

22. Kovač Z. Clinical pathophysiology - etiopathogenetic nodes [in Croatian]. Zagreb: Medicinska naklada; 2013.

23. Kovač Z. Algorithmic and nodal study and identification of the physiology of disease [in Croatian]. Liječničke novine. 2014;14:(128)34-6. 